\title{
INVESTIGATION OF JUNCTION PROPERTIES OF CdS/CdTe SOLAR CELLS AND THEIR CORRELATION TO DEVICE PROPERTIES
}

\author{
R.G. Dhere, Y. Zhang, M.J. Romero, S.E. \\ Asher, M. Young, B. To, R. Noufi and T.A. \\ Gessert.
}

\section{Acknowledgements- K. Ramanathan, T. Coutts. DOE contract \# DE-AC36-99G010337}




\section{Objective - Junction Studies}

- Understand the nature of the junction in the CdTe/CdS device

-Correlate the device fabrication parameters to the junction formation

-Develop a self consistent device model to explain the device properties

Detailed analysis of $\mathrm{CdS} / \mathrm{CdTe}$ and $\mathrm{SnO}_{2} / \mathrm{CdTe}$ devices prepared using CSS CdTe. 


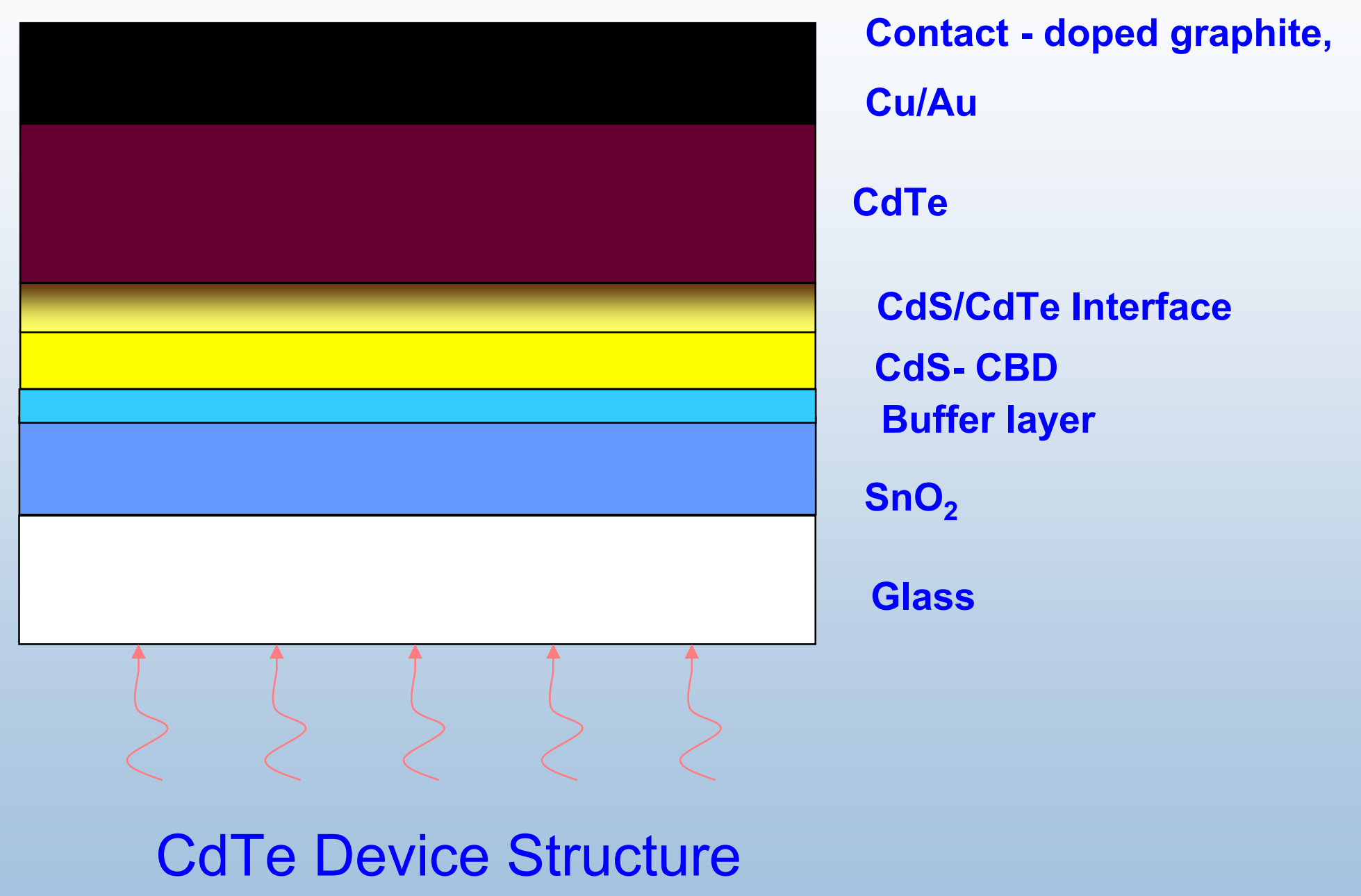


$n^{+}-p$ device model for CdS/CdTe device (6/95)based on blue QE loss:

- One sided junction with depletion width entirely in CdTe.

- Only field assisted collection.

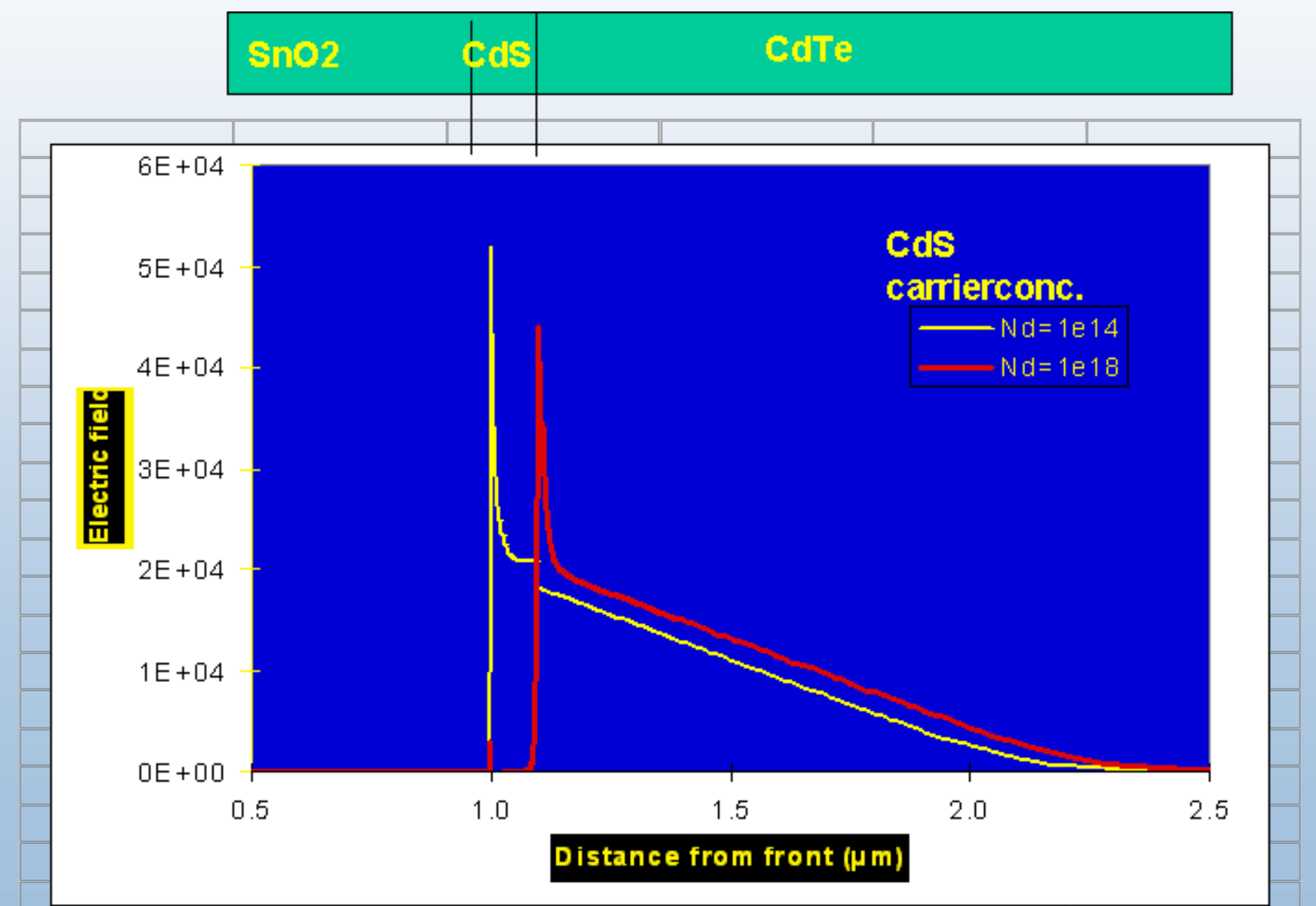




\section{Problems with the $\mathrm{n}^{+}-\mathrm{p}$ model}

-Phenomenological Model - can explain the device performance but without physical basis.

-CBD CdS has carrier concentration around $10^{13} / \mathrm{cm}^{3}$ which is even less than CdTe

Here we present our interface/junction analysis using Secondary Ion Mass Spectrometry (SIMS), Modulated reflectance techniques and Electron Beam Induced Current (EBIC) to elucidate the junction properties. 


\section{SIMS Results}

- Roughness of the samples (RMS - 0.5 $\mu \mathrm{m})$ makes it impossible to resolve the features at $\mathrm{CdS} / \mathrm{CdTe}$ interface.

- NREL SIMS and Microscopy groups developed sample preparation with polishing to improve the interface resolution. 


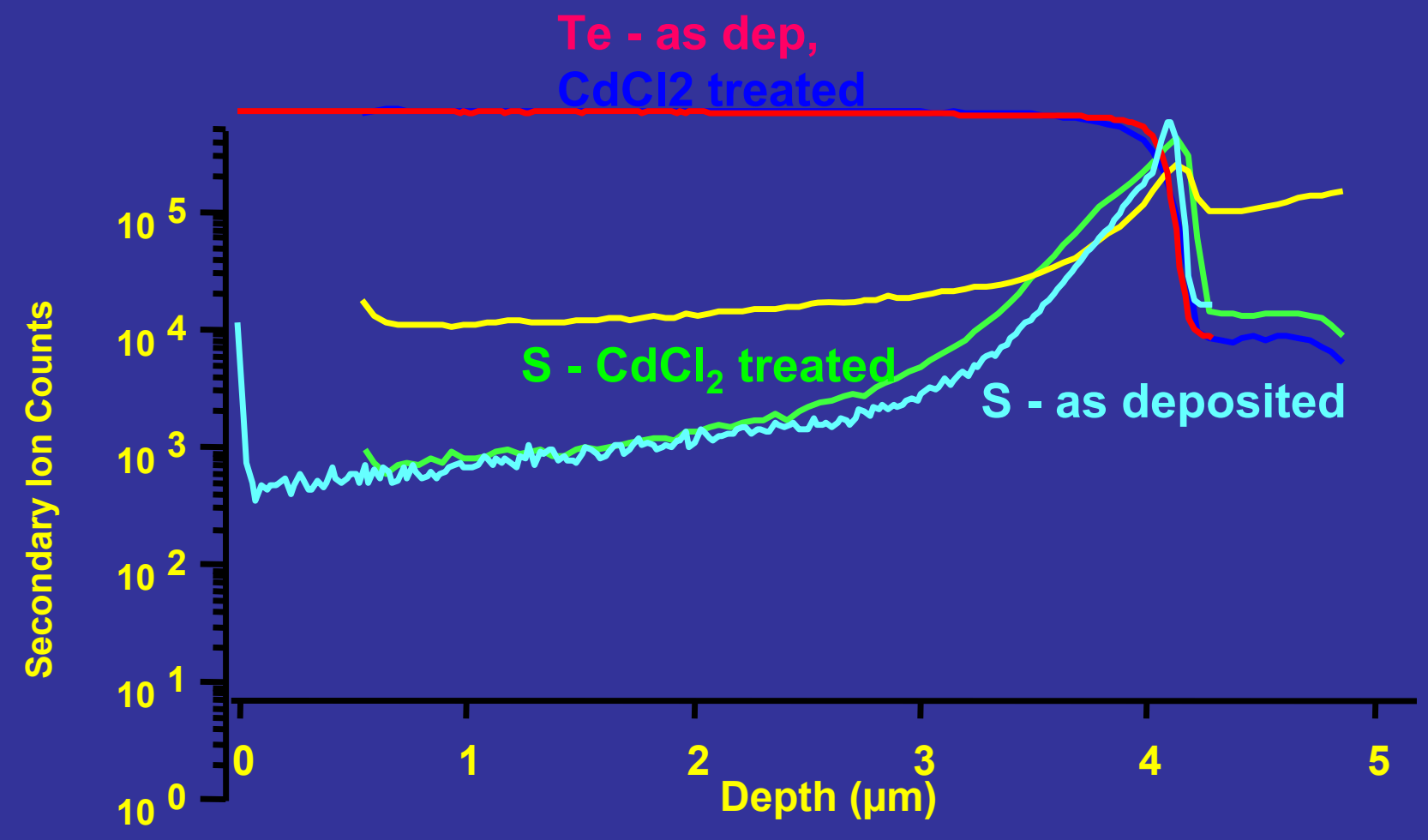




\section{Observations}

- Interdiffusion at CdS/CdTe interface increases with $\mathrm{T}_{\text {sub }}$ and $\mathrm{CdCl}_{2} \mathrm{HT}$

- Accumulation of $\mathrm{Cl}$ at $\mathrm{CdS} / \mathrm{CdTe}$ interface after $\mathrm{CdCl}_{2} \mathrm{HT}$. Level of $\mathrm{Cl}$ increases with level of HT

- $\mathrm{Cl}$ is a n-type dopant in both CdS and CdTe; also in the intermixed alloy 


\section{Photo- or Electro-Modulated Reflectance (PR or ER)}

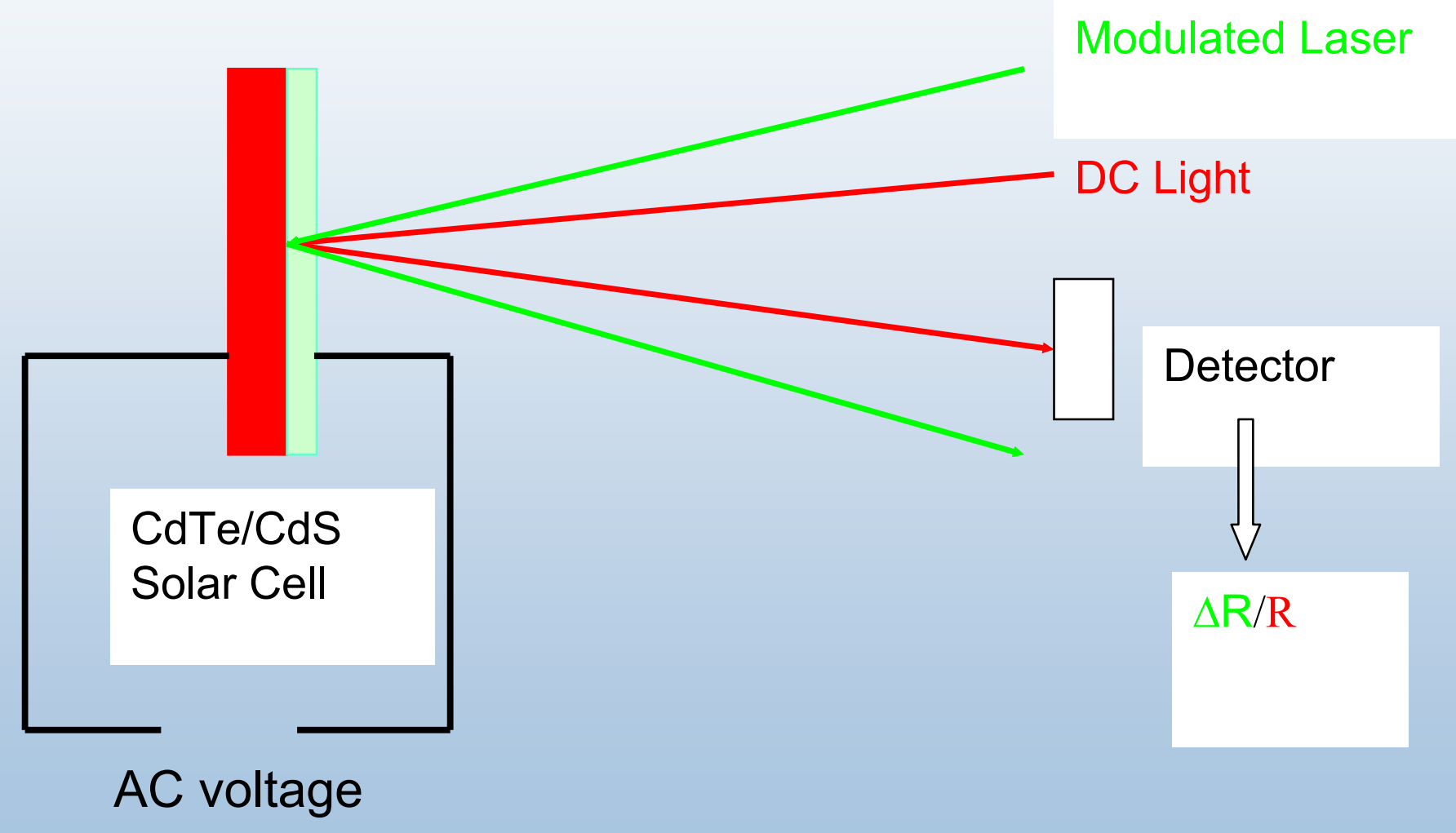




\section{Reflectance modulation}

$$
\begin{aligned}
& R=\left|\frac{n-n_{a}}{n+n_{a}}\right| \\
& \mathrm{n}^{2}=\varepsilon_{1}+\mathrm{i} \varepsilon_{2}, \quad \mathrm{n}_{\mathrm{a}}{ }^{2}=\varepsilon_{\mathrm{a}} \text { (real) }
\end{aligned}
$$

Near band-gap $\Rightarrow$ major contribution is from $\Delta \varepsilon_{1}$ :

$$
\frac{\Delta R}{R} \approx \alpha \Delta \varepsilon_{1}
$$




\section{Fitting Modulation Reflectance Spectrum}

$$
\begin{aligned}
& \Delta \varepsilon_{1}=\frac{2 e^{2} \hbar^{2}\left|\vec{e} \cdot \vec{P}_{c v}\right|^{2}}{m^{2}(\hbar \omega)^{2}}\left(\frac{2 \mu_{0}}{\hbar^{2}}\right)^{3 / 2} \sqrt{\hbar \Omega_{0}}\left(G\left(\frac{E_{g}-\hbar \omega}{\hbar \Omega_{0}}\right)-\sqrt{\frac{E_{g}-\hbar \omega}{\hbar \Omega_{0}}} F\left(\frac{E_{g}-\hbar \omega}{\hbar \Omega_{0}}\right)\right) \\
& F(\eta)=\pi\left[A_{i}^{\prime 2}(\eta)-\eta A_{i}^{2}(\eta)\right] \\
& G(\eta)=\pi\left[A_{i}^{\prime}(\eta) B_{i}^{\prime}(\eta)-\eta A_{i}(\eta) B_{i}(\eta)\right]
\end{aligned}
$$

Shen \& Pollak, Phys. Rev. B 42, 7097 (1990) 


\section{Photo-reflectance}

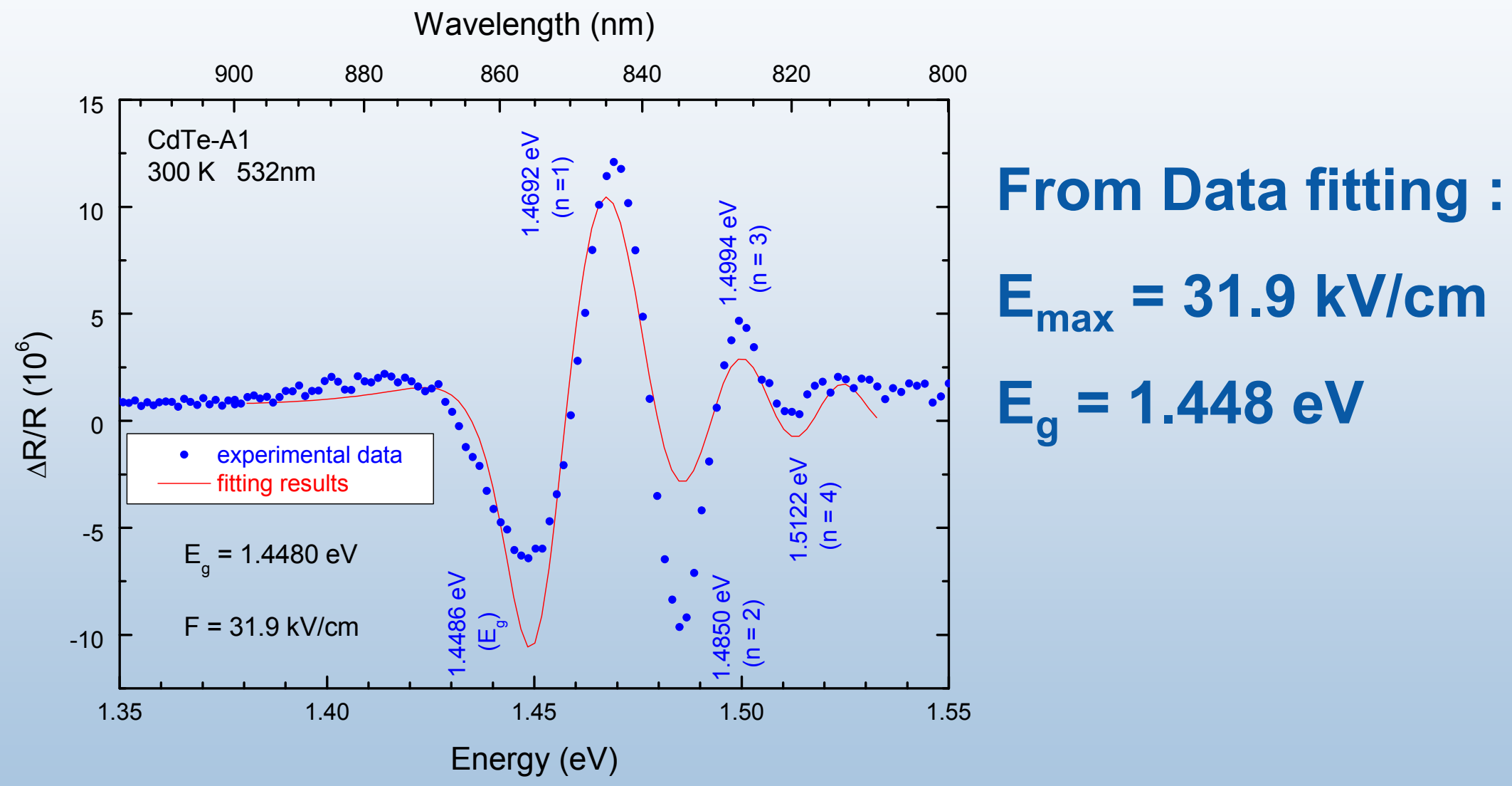




\section{Electro-reflectance}

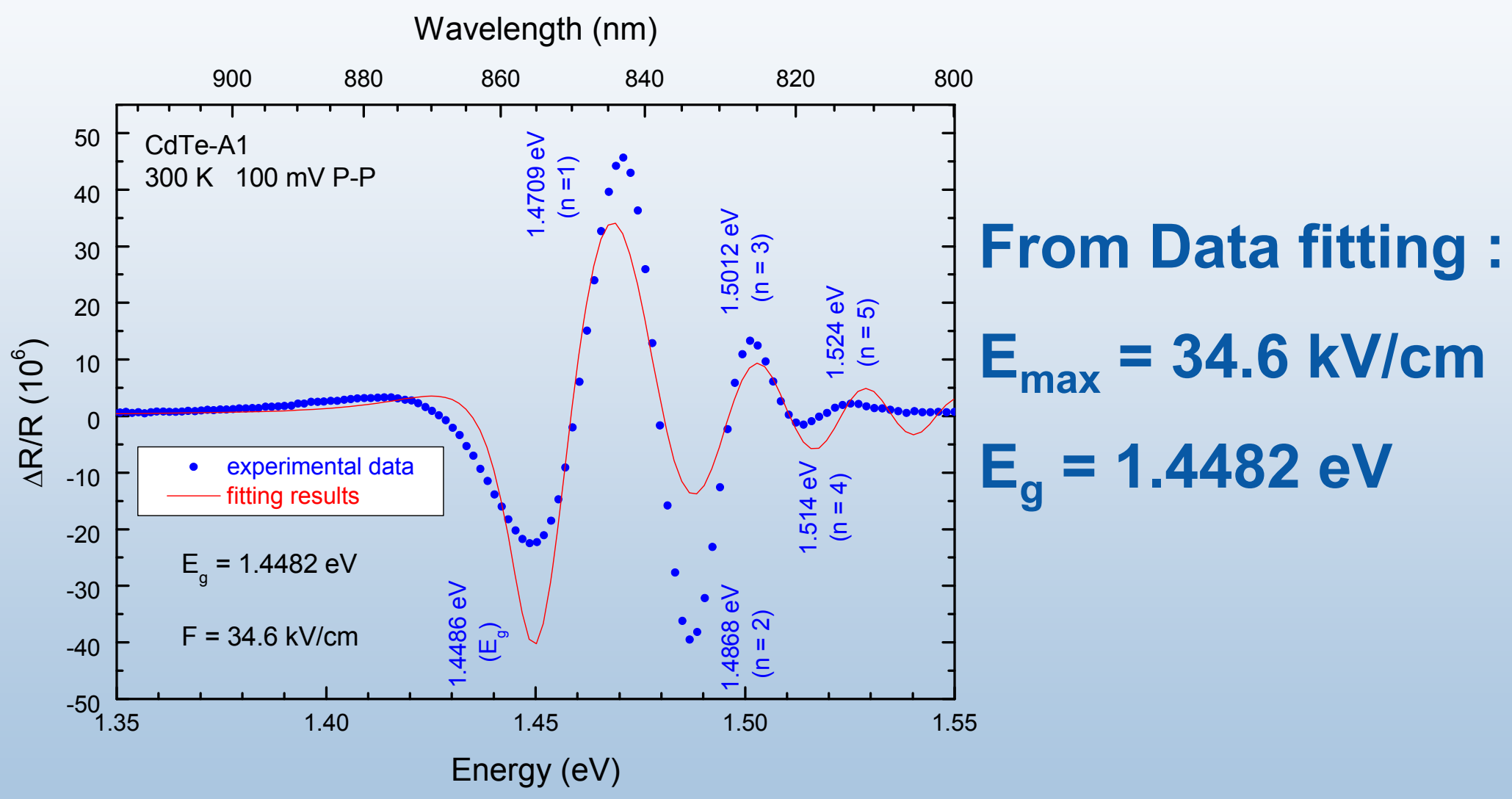




\section{Effect of $\mathrm{CdCl}_{2}$ treatment (by PR)}

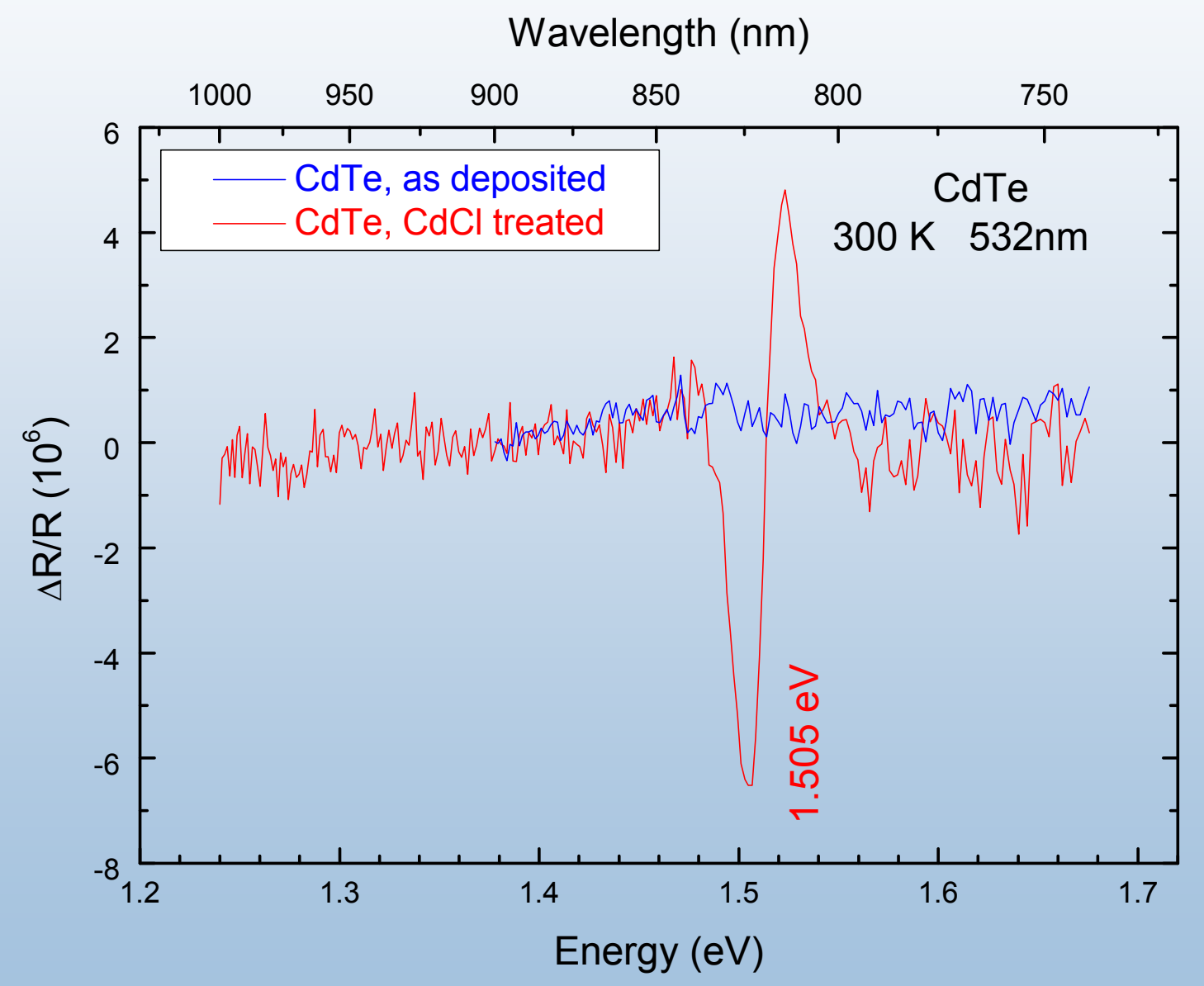




\section{Modulated Reflectance}

- Modulated electro-reflectance and photoreflectance studies identify a region of high electric field $(\sim 32-35 \mathrm{kV} / \mathrm{cm})$ for high efficiency CdS/CdTe devices. The field is present in the region of $1.45 \mathrm{eV}$ material.

- $\mathrm{SnO}_{2} / \mathrm{CdTe}$ devices do not show high field region

The high field region corresponds to Te-rich CdSTe alloy. 


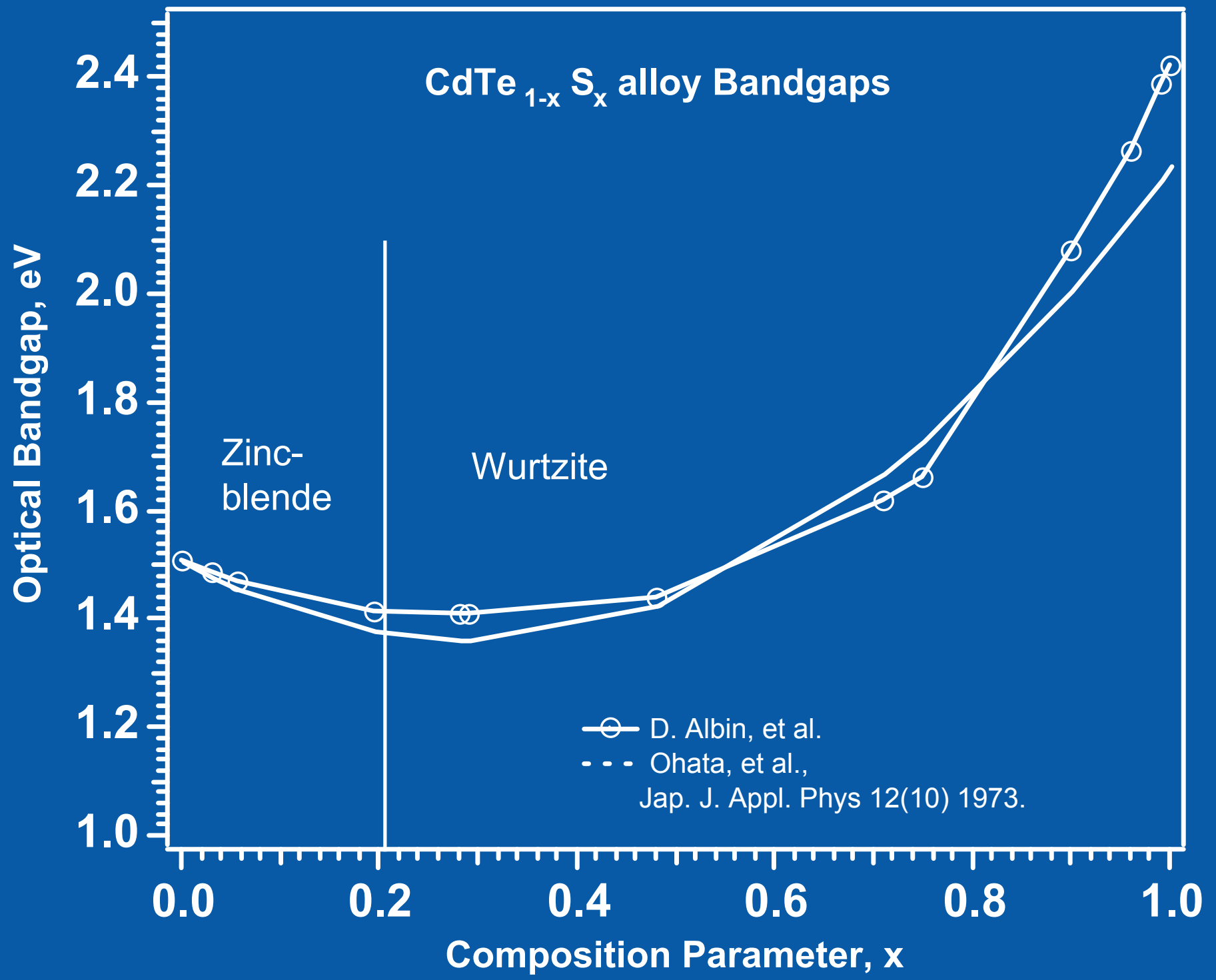


From $\mathrm{E}_{\max }=32 \mathrm{kV}$ and depletion width on $\mathrm{p}$-side $=3 \mu \mathrm{m}$ (base on $\mathrm{C}-\mathrm{V}$ and $\mathrm{EBIC}$ results)

Using $\mathrm{E}_{\max }=\mathrm{qN}_{\mathrm{A}} \mathrm{X}_{\mathrm{p}} / \varepsilon_{\mathrm{s}}$

Gives $\mathrm{N}_{\mathrm{A}}=5.5 \times 10^{14} \mathrm{~cm}^{-3}$

Evaluation of $\mathrm{N}_{\mathrm{D}}$ based on SIMS and EBIC results 


\section{EBIC}

- SEM and HR-EBIC measurements performed on high $\mathrm{V}_{\text {oc }}(835 \mathrm{mV})$ device.

- Measurements on the cross-section of the device. Shows EBIC response close to CdS/CdTe interface. 


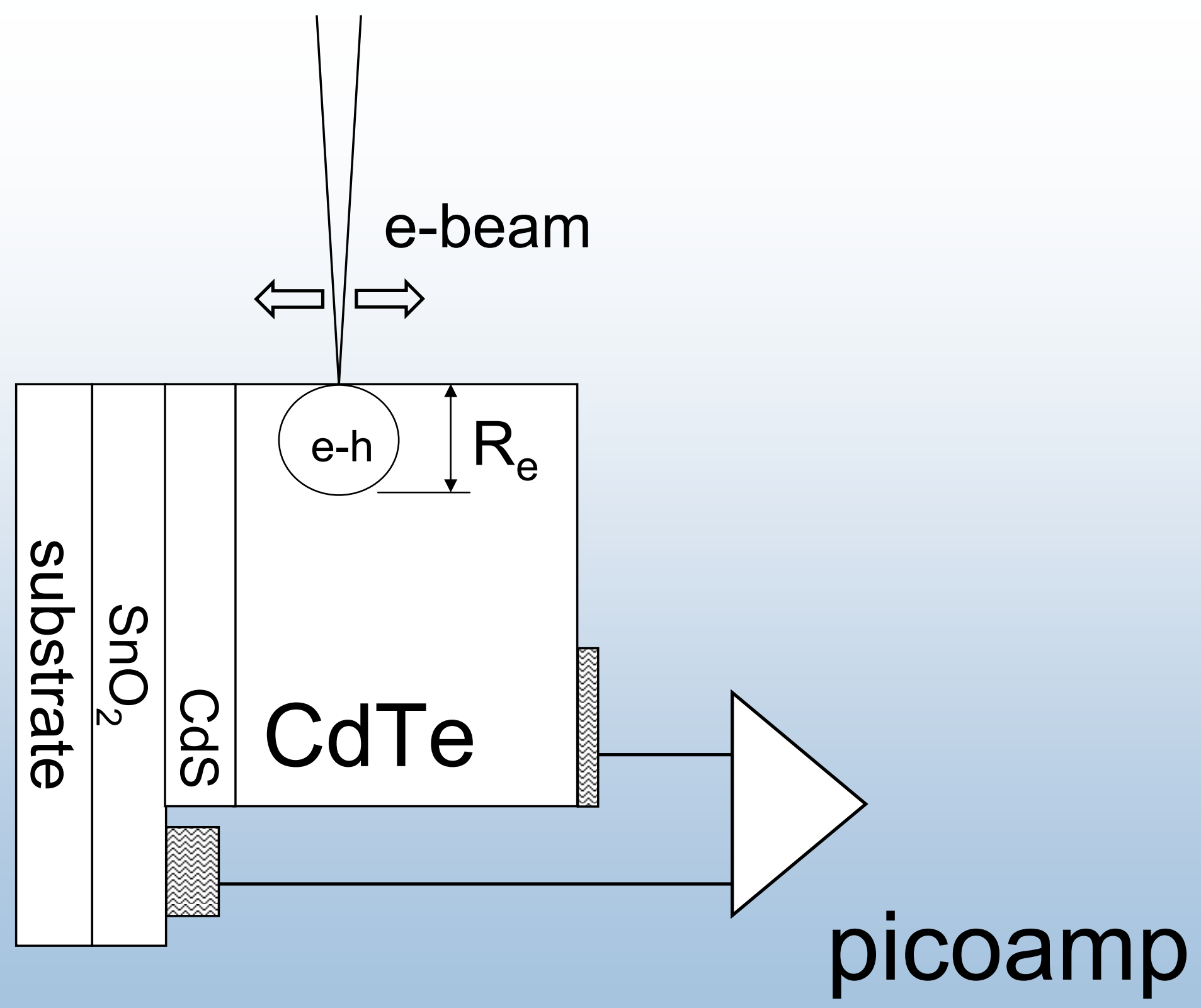




\section{Electron-beam-induced-current}

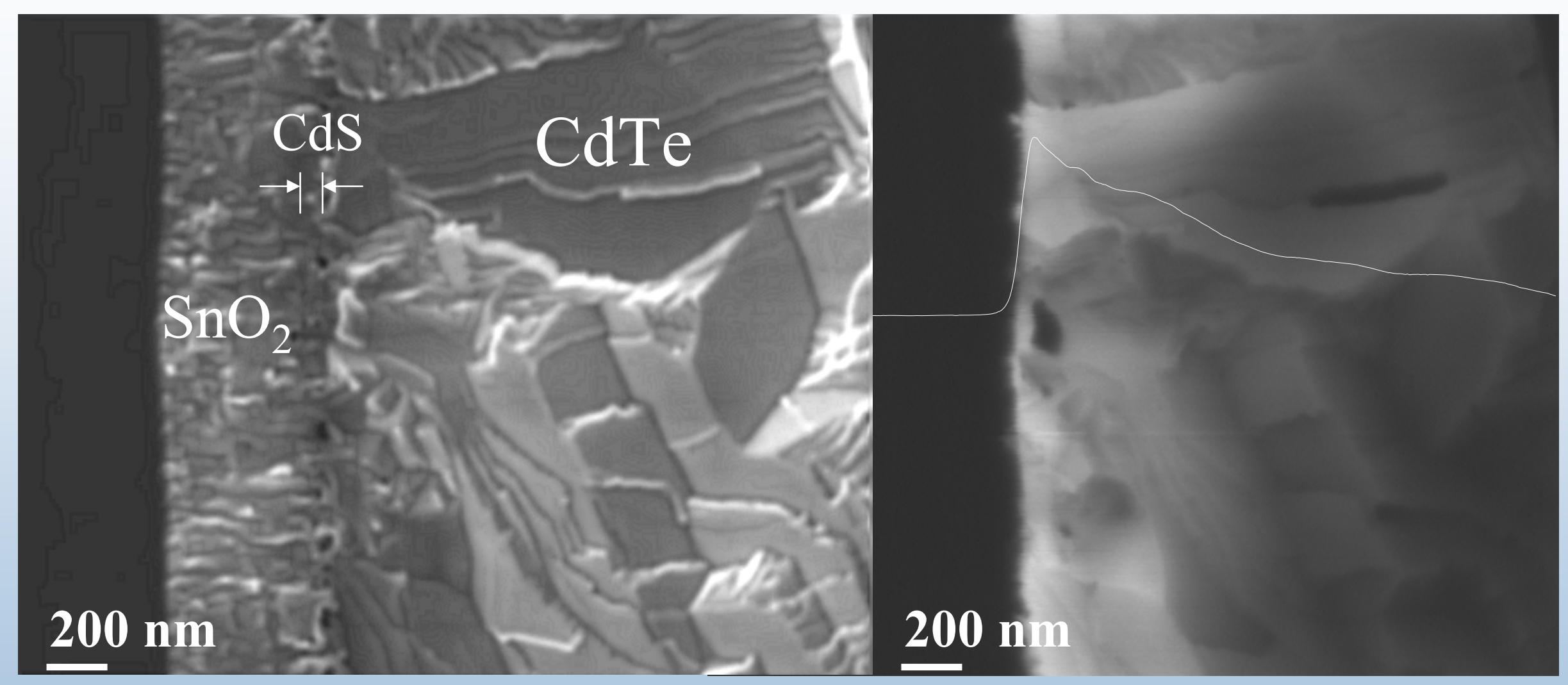

HREBIC 
Device model

$\mathrm{SnO}_{2}$
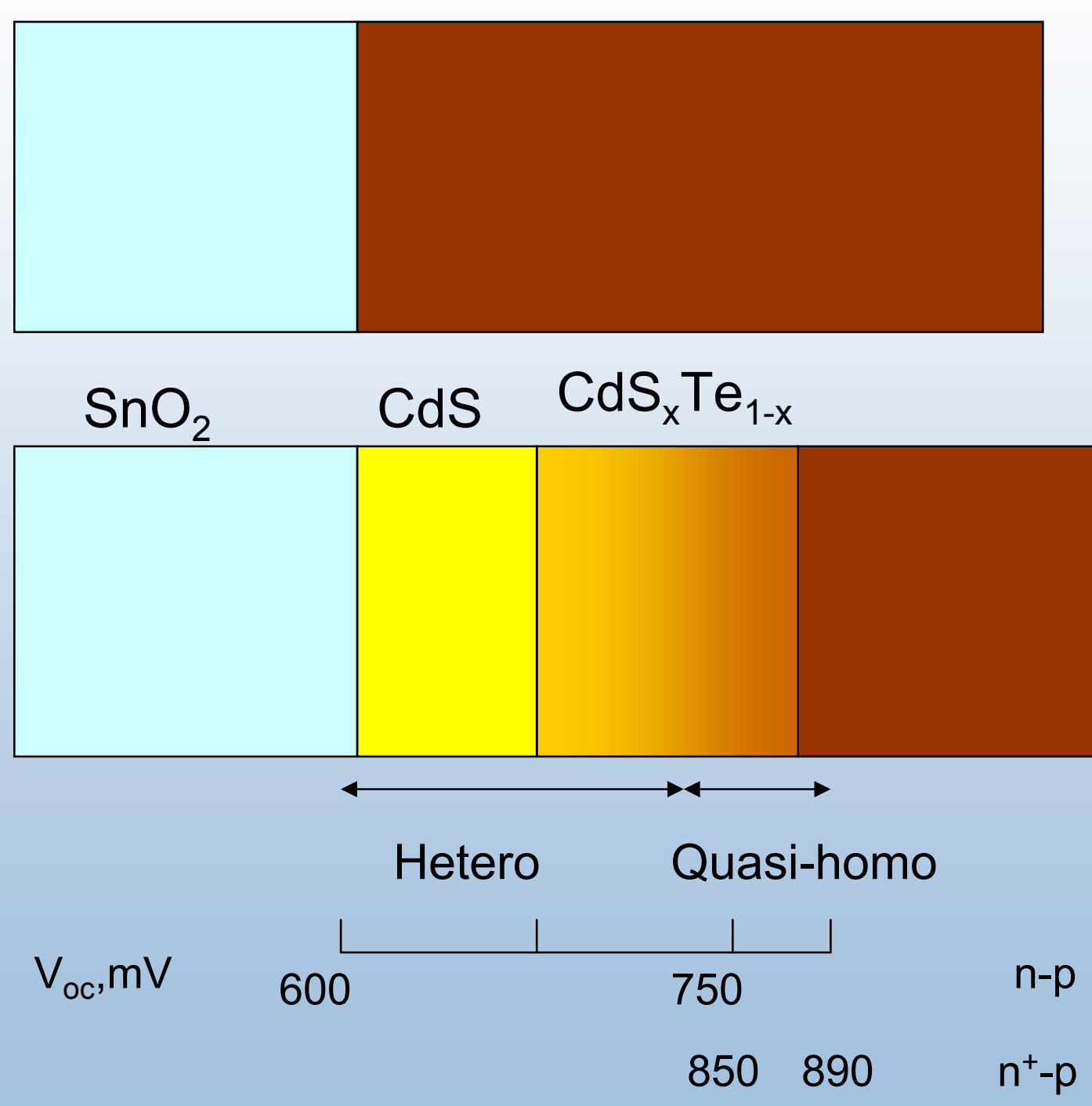

CdTe 


\begin{tabular}{|l|l|}
\hline Device structure & $\mathrm{V}_{\text {oc }}, \mathrm{mV}$ \\
\hline $\mathrm{SnO}_{2} / \mathrm{CdTe}$ & $600-650$ \\
\hline $\mathrm{CdS} / \mathrm{CdTe}$ as dep & $720-750$ \\
\hline $\mathrm{CdS} / \mathrm{CdTe}$ w/ $\mathrm{CdCl}_{2}$ & $840-850$ \\
\hline
\end{tabular}

- Lower $\mathrm{V}_{\text {oc }}$ devices are true hetero-junctions, whereas the devices with $\mathrm{CdCl} 2$ treatment have a junction between $\mathrm{n}^{+}$Te-rich CdSTe alloy (doped with $\mathrm{Cl}$ ) and p-type $\mathrm{CdTe}$ with compatible cubic structure i.e. quasihomojunction.

- A true hetero-junction CdS/CdTe device performance will be dominated by interface defects at the hetero-interface which will be within the depletion region. This may be the case for as deposited devices fabricated at lower temperatures and $\mathrm{SnO}_{2} / \mathrm{CdTe}$ devices giving low Voc.

- Role of CdS is mainly to produce Te rich alloy layer that gets doped to ntype during $\mathrm{CdCl}_{2}$ process and passivation of the surface, 